\title{
Aircraft Measurements of Medium-Range Transport of Air Pollutants over Complex Terrain
}

\author{
Tokiyoshi Toya, Fujio Kimura and Nobuhiko Murayama* \\ Meteorological Research Institute, Tsukuba, Ibaraki 305, Japan \\ (Manuscript received 26. June 1985, in revised form 18, April 1986)
}

\begin{abstract}
A series of aircraft measurements of the three-dimensional distribution of air pollutants and meteorological elements was conducted each summer of 1980,1981 and 1982 in the Inland Sea area of Japan in order to examine the medium-range transport processes due to local circulations.

The data show that polluted air is horizontally distributed over almost all of the Sea and is confined to levels below $1000 \mathrm{~m}$ in the early morning. The polluted air is transported to upper levels up to $3000 \mathrm{~m}$ in the evening by upslope winds and/or the sea breeze on the Shikoku side of the Sea. Developed cumulus clouds over the mountains seem to contribute to the vertical transport of ozone and the scavenging of aerosols.

The structure of the internal boundary layers formed over the complex terrain is also analyzed. The results agree quite well with a simple model simulation.
\end{abstract}

\section{Introduction}

The Seto Inland Sea is located in the western part of Japan extending nearly $300 \mathrm{~km}$ from west to east between the districts of Shikoku and Chugoku. As shown in Figure 1, the Shikoku side is walled by mountains $1000-2000 \mathrm{~m}$ high with very steep slopes. Mountains in the Chugoku district, on the other hand, are comparatively low and gently sloping. In general, the local circulation in the Inland Sea area has a tendency to develop more markedly on the Shikoku side of the Inland Sea due to steep slopes. The local circulation on the Chugoku side, on the other hand, is modified more significantly by the east-west flow along the Inland Sea caused by the synoptic wind.

Since many industrial facilities are dotted along the coast (Figure 1), it is very important to clarify how emitted pollutants are dispersed and transported by the local circulation. To support this investigation, aircraft measurements

\footnotetext{
* Present affiliation: Meteorological Satellite Center, Kiyose, Tokyo 204, Japan
}

of meteorological elements and air pollutants were carried out in addition to surface and upper air observations.

Three-dimensional pollution studies by instrumented aircraft have been done by Edinger (1973), Gloria et al. (1974), Husar et al. (1977) and Blumenthal et al. (1978) in the Los Angeles air basin on smoggy days. Blumenthal et al. mapped out the three-dimensional distribution of air pollutants in the basin and related the movement of the polluted air to the sea breeze. They showed that pollutants are transported downwind to inland areas by the sea breeze, and observed the highest ozone concentrations of the day not only ahead of the marine front but also just above the marine layer.

In Japan, Mizuno et al. (1979), Tsuruta (1983) and Wakamatsu et al. (1983) made threedimensional aircraft surveys of the pollutants over the Kanto Plain covering the Tokyo Metropolitan area and analyzed the relationship between the pollutant concentration patterns and the sea/land breeze. Wakamatsu showed that the maximum ozone concentrations appeared at an altitude of $500 \mathrm{~m}$ in the morning and were 


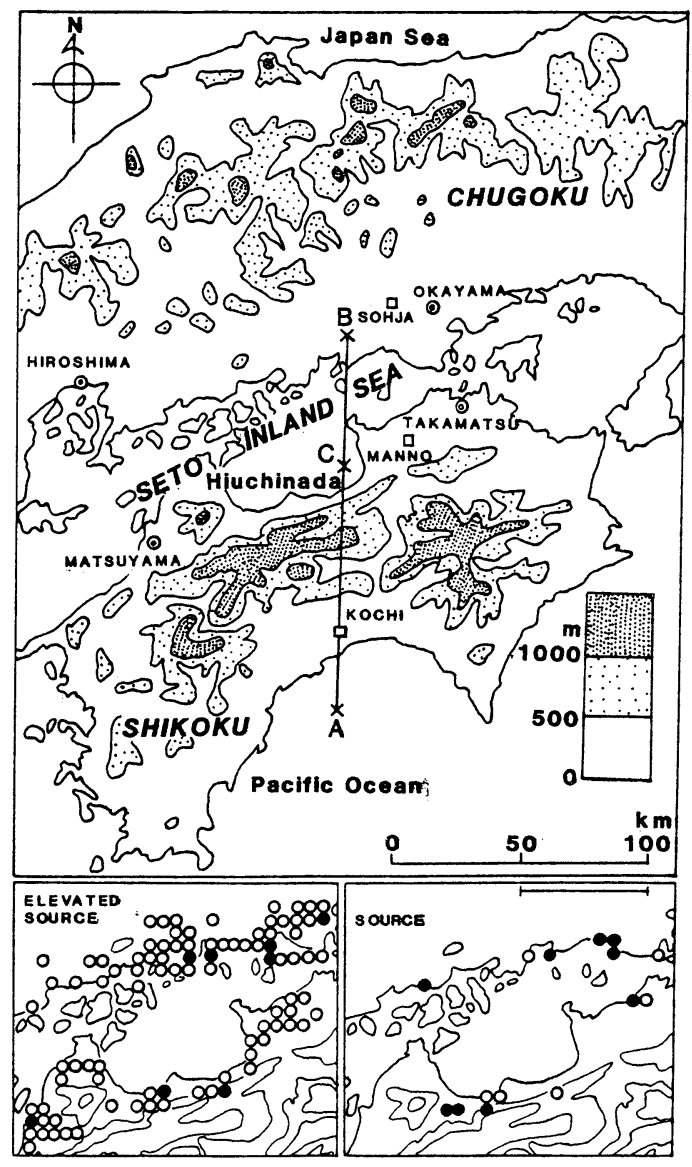

Fig. 1 Top: Topographical map of the Hiuchinada area of the Seto Inland sea. The line A-B shows the flight course in 1982. Bottom: Distribution of NOx sources. Surface sources (left; automobile and stationary sources whose stack heights are less than $100 \mathrm{~m}$ ) and elevated sources (right). Open circles denote $10-100 \mathrm{~m}^{3} / \mathrm{h}$, closed circles more than $100 \mathrm{~m}^{3} / \mathrm{h}$. found at higher altitudes $(z=1200 \mathrm{~m})$ in the afternoon when the sea breeze moved further inland. In comparison with these investigations over the Plain, more complicated transport processes can be expected over complex terrain such as the Inland Sea area.

In this paper, we intend to describe the characteristics of the measured horizontal and vertical distributions of air pollutants, suggest a model of transport processes, and then refer to the abrupt change of pollutant concentration in convective cloud. We also analyze the structure of the internal boundary layers with a simple model simulation.

\section{Experimental data}

The experimental studies were performed in the central part of the Inland Sea and its coastal regions for several days each summer of 1980, 1981 and 1982. Aircraft measurements were aimed at understanding the actual situation of three-dimensional pollutant diffusion and its diurnal variation. In 1980, horizontal distributions of air pollutants were measured as a preliminary study in the lower atmosphere over Hiuchinada, in the central part of the Inland Sea. In 1981, vertical profiles as well as horizontal distributions of air pollutants were measured up to upper levels (200 to $2000 \mathrm{~m}$ ) and various kinds of supplementary measurements were performed on transects between Osaka and Hiuchinada. A typical flight course in 1981 is shown in Figure 2a. In 1982, the aircraft flights were chiefly designed to obtain vertical cross-sections of air pollutant concentra-

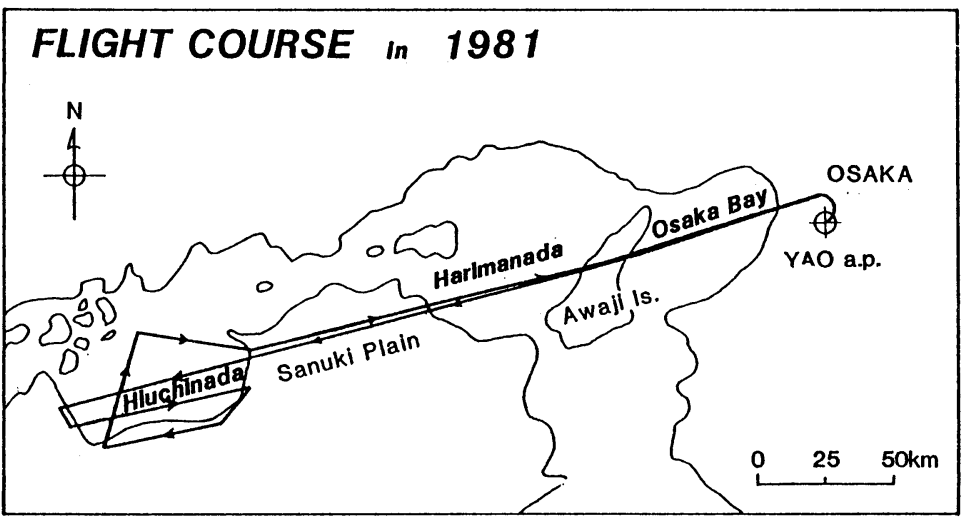

Fig. 2a Typical flicht course for the observations in 1981. 


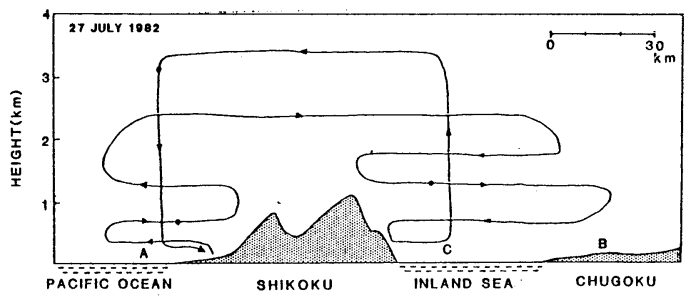

Fig. 2b A side view of the flight course in 1982 .

tions by flying as in Figure $2 \mathrm{~b}$ along the transect between $\mathrm{A}$ and $\mathrm{B}$ in Figure 1. The list of experimental flights is shown in Table 1 . The weather conditions during observation periods were typical of summer in Japan, and the local circulation with weak synoptic wind was observed.

Air from the nose-cone of the aircraft was sucked into a distribution manifold through a Teflon tube $(25 \mathrm{~mm}$ in diameter) and then supplied to both the air pollution measuring system (NO meter, NOx meter and ozone meter) and a particle counter. The instruments used are tabulated in Table 2 and installation on the aircraft body is shown in Figure 3. The measured data were essentially digitized in real time and recorded on magnetic tapes.

Details of the experimental data are described in a technical report of the Meteorological Research Institute, No. 11 (Murayama et al., 1984).

\section{Results and discussion}

\section{Horizontal distribution of air pollutants}

Figures $4 a-4 c$ show a typical example of the horizontal distributions of NOx, ozone and aerosol measured at a level of nearly $300 \mathrm{~m}$ at about 1600 JST, 19 August 1981. Surface winds

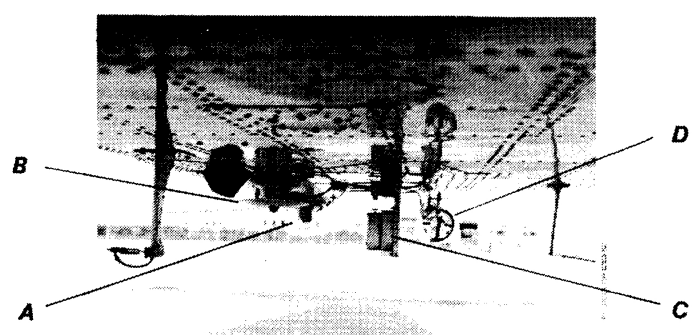

Fig. 3 Photograph of the installation of meteorological instruments in 1982. Pyranometer (A), Pyrgeometer (B), Sensor head of Lyman-alpha hygrometer (C) and Platinum resistance thermometer (D).

by AMeDAS (the Automated Meteorological Data Acquisition System) and winds at the $300 \mathrm{~m}$ level by PIBAL are added to the figures. It can be seen that a large portion of air pollutants stay along the coast of Hiuchinada due to the weak sea breeze. The concentration of NOx is nearly zero in the central part of Hiuchinada, and NOx originating on the Shikoku side does not seem to be transported to the Chugoku side. The distribution of ozone, on the other hand, is uniform over almost all of Hiuchinada. The concentration of particles $(0.3-0.5 \mu \mathrm{m}$ in diameter) is high over the coast and extremely low over the sea. The pattern of the distribution is similar to that of ozone on the whole.

The difference in distributions of NOx and ozone can be explained by the air chemistry. Since NOx has a short life compared with ozone in the daytime, NOx emitted at the Shikoku side remains merely as plumes or puffs which

Table 1 List of experimental flights in 1981-82.

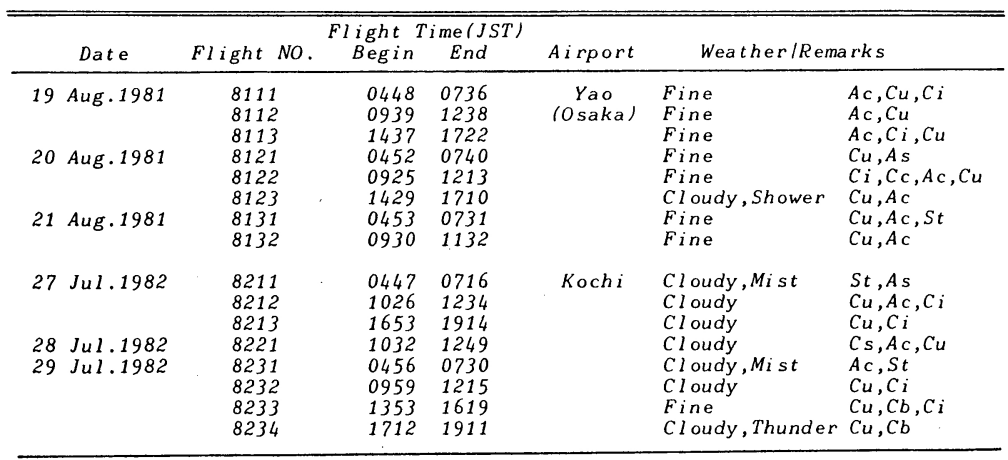


Table 2 Aircraft instrumentation.

\begin{tabular}{|c|c|}
\hline \multirow{2}{*}{$\begin{array}{r}\text { Paramet er } \\
\text { mea sured } \\
\end{array}$} & Inst rument \\
\hline & 1982 \\
\hline Aircraft & Cessna 404 \\
\hline Position & Loran-C navigation system \\
\hline Alt it ude & Pressure altimeter \\
\hline At titude & Vertical \& rate gyro \\
\hline A ir t emp. & Platinum resistance thermometer \\
\hline Humidity & EGEG hygromet er, Ly-a hygromet er \\
\hline Surface temp. & Infrared radiat ion thermomet er \\
\hline Radiation & Pyranomet er,Pyrgeomet er \\
\hline Aerosol & Particle counter RION KC-01 \\
\hline Air pollutants & NO meter, NOx meter, Ozone meter ( chemiluminescence) \\
\hline \multirow[t]{2}{*}{ Surface image } & VTR syst em \\
\hline & Air sampling system, Data acquisition system \\
\hline
\end{tabular}

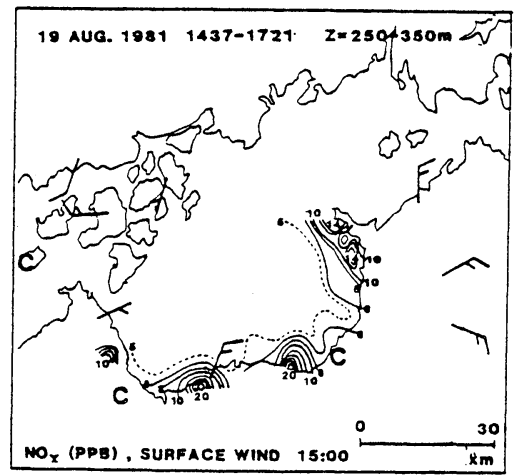

Fig. 4a Distribution of NOx observed at a level of nearly $300 \mathrm{~m}$ in the afternoon on 19 August 1981 and surface winds by AMeDAS. A half barb is equivalent to $1 \mathrm{~m} / \mathrm{s}$ and.C indicates calm $(<0.9 \mathrm{~m} / \mathrm{s})$.

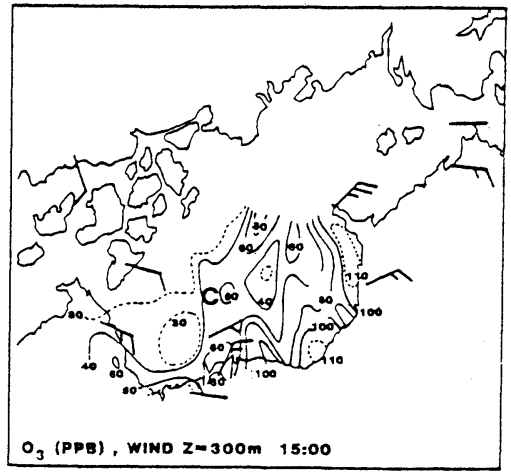

Fig. 4b Same as in Fig. 4a but ozone and winds at a level of $300 \mathrm{~m}$ by PIBAL.

roughly correspond to emission sources. Ozone, which keeps quite a high concentration during medium-range transport because of its long life, is well diffused over almost all of Hiuchinada by the local circulation.

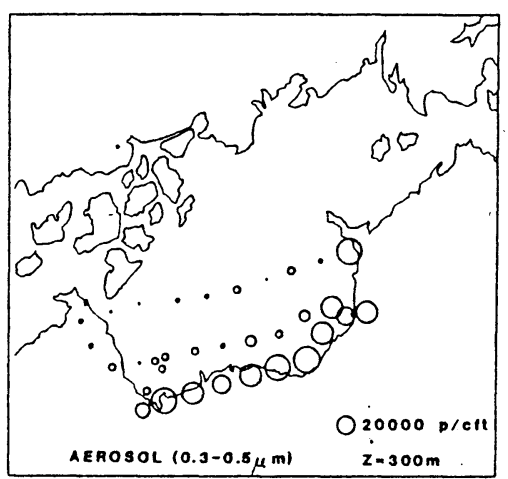

Fig. 4c Same as in Fig. 4a but aerosol. The area of each circle is proportional to the concentration. The reference circle is equivalent to 20000 particles per cubic feet.

The vertical transport process due to the local circulation

The vertical profiles of ozone, aerosol and absolute humidity obtained by the measurements at the point $\mathrm{C}$ in Figure 1 on 27 and 29 July 1982 are shown in Figures $5 \mathrm{a}$ and 5b, respectively. Figure $5 \mathrm{c}$ shows the vertical profiles on those days on the other side of Shikoku (the Pacific Ocean side), where far fewer emission. sources are located. Therefore, the concentrations at upper levels over $1000 \mathrm{~m}$ are considered to be background values. Comparing Figure 5a with Figure 5c, we can find the following characteristics common to the three kinds of profiles.

(1) The difference of concentrations between early morning and midday is small at upper levels, where ozone concentration is almost equal to the background value. At lower levels below $1000 \mathrm{~m}$, concentrations of pollutants 
are increasing with time.

(2) In the afternoon, polluted air is transported to the upper layer and extends up to $3000 \mathrm{~m}$ when evening comes.

(3) In the evening, concentrations in the layer $1500-2000 \mathrm{~m}$ are comparatively small, while those at levels of 2000-3000 m are large.
We can find the same characteristics clearly in the vertical profiles observed on 29 July 1982 (Figure 5b). These features are attributable to the vertical transport of pollutants by the local circulation as described later.

The vertical distributions of air pollutants measured in the early morning and in the after-
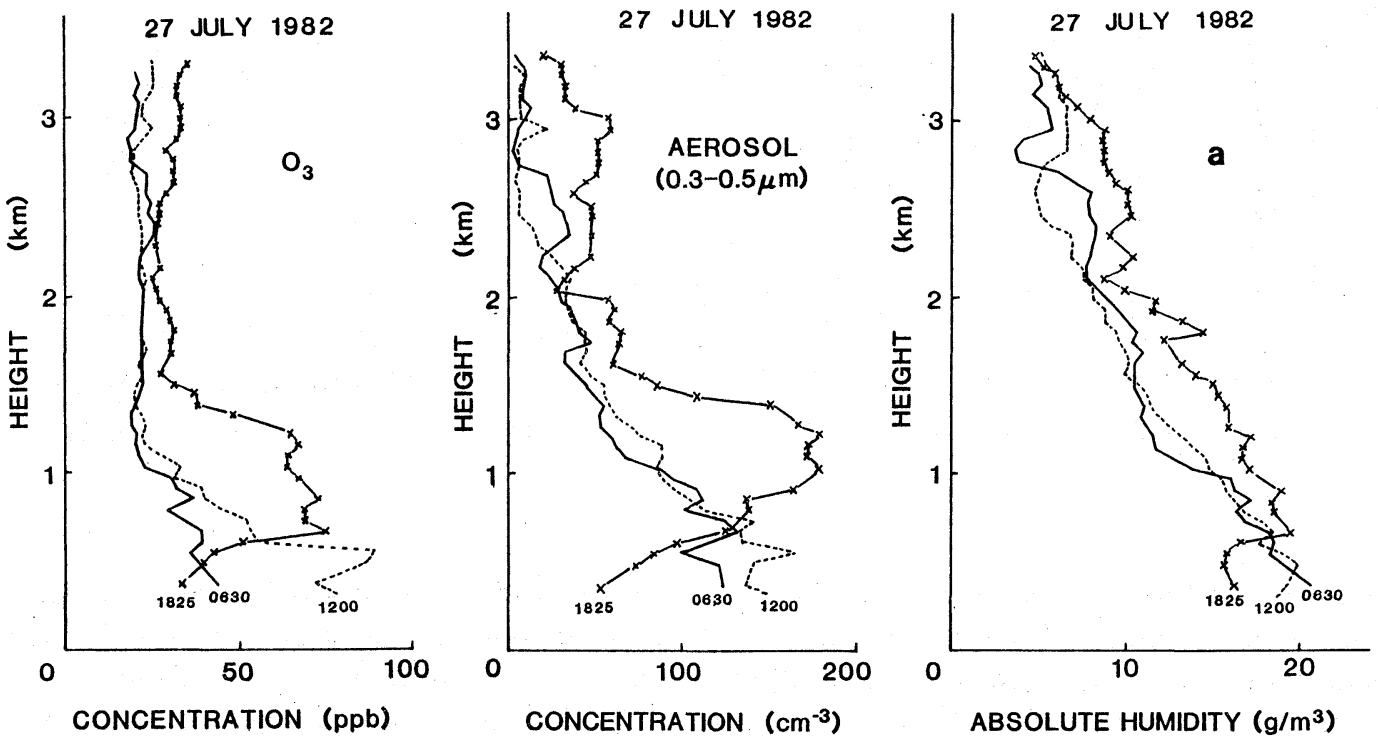

Fig. 5a Vertical profiles of concentrations observed at the point C in Fig. 1 on 27 July 1982.
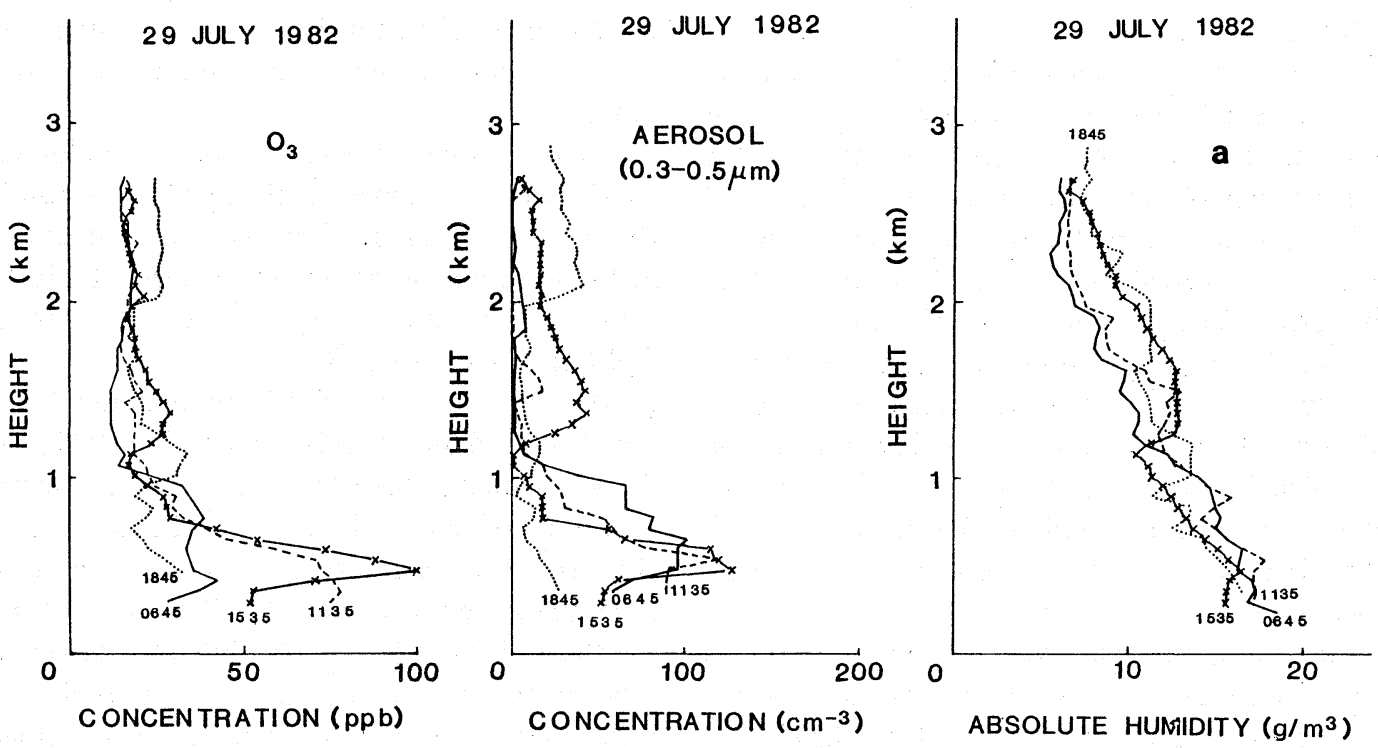

Fig. 5b Same as in Fig. 5a but on 29 July 1982. 

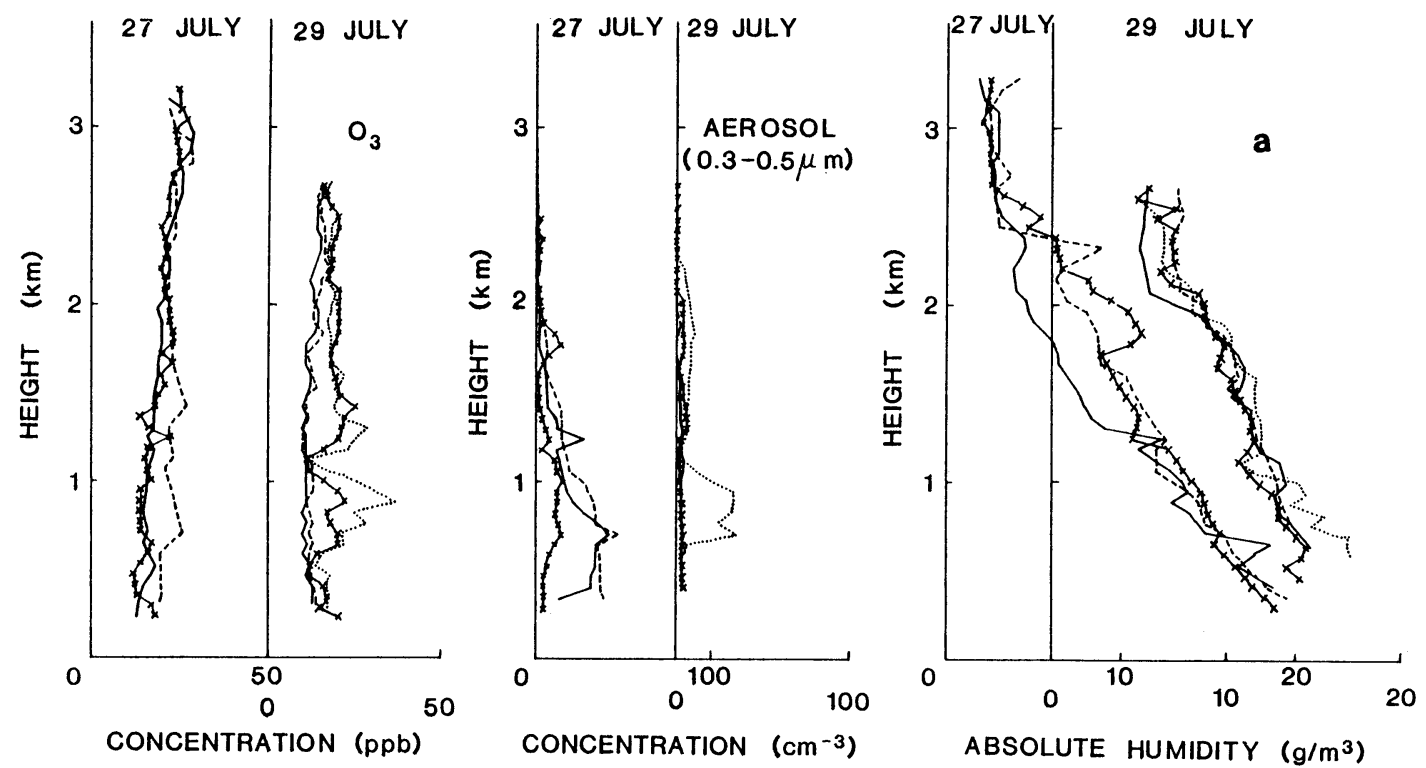

Fig. 5c Vertical profiles of concentrations observed on the Pacific Ocean side on 27 and 29 July 1982.

noon on 29 July 1982 are shown in Figure 6. The vertical profiles of the north-south component of wind velocity determined by PIBAL at the stations indicated in Figure 1 are also shown in the figure. The weather condition was basically similar to that on 27 July 1982, although it was comparatively unstable and cumulonimbus clouds were scattered late in the afternoon.

In the early morning, the wind in the lower layer at Kochi is calm. Downslope winds and/or land breezes are seen at the other stations. In the Hiuchinada area the high concentration of NOx is confined to levels below $500 \mathrm{~m}$, while ozone is stratified between $500 \mathrm{~m}$ and $1000 \mathrm{~m}$ in height. The concentration of aerosol is high in the layer below $1000 \mathrm{~m}$ where aerosol is horizontally distributed. A high concentration of aerosol is also seen in the lower layer on the Pacific Ocean side. In general, the polluted air is considered to be spread out all over Hiuchinada and confined to levels below $1000 \mathrm{~m}$ in the early morning.

In the afternoon, NOx is greatly reduced by chemical reaction as well as diffusion. Ozone and aerosol, however, exist in a thick layer over the Chugoku and Shikoku sides of Hiuchinada and extend to heights of up to $2000 \mathrm{~m}$. The layer of polluted air is thinner over the central part of Hiuchinada as a result of subsidence by fully developed upslope wind and/or sea breeze. The air pollutants transported to upper levels over the Shikoku mountains return gradually to Hiuchinada via the southwesterly upper level wind. As a result, two high-concentration levels appear over Hiuchinada in the evening: one near the surface, and one above the mountain range.

There is some possibility that air pollutants transported to upper levels remain till sunrise the next morning. In fact, we observed quite a high concentration of ozone at a level of $2800 \mathrm{~m}$ above the mountain range in the early morning flight on 21 August 1981.

The aircraft surveys of the pollutants over the Kanto Plain by Mizuno et al. (1979) and Wakamatsu et al. (1983) also indicate the vertical transport of air pollutants by the sea breeze. However, the height of the highly polluted air is comparatively low over the Plain $(z=1200 \mathrm{~m})$. On the Shikoku side of the Inland Sea, on the other hand, the polluted air is transported much higher by the complex wind system of sea breeze and upslope wind. 

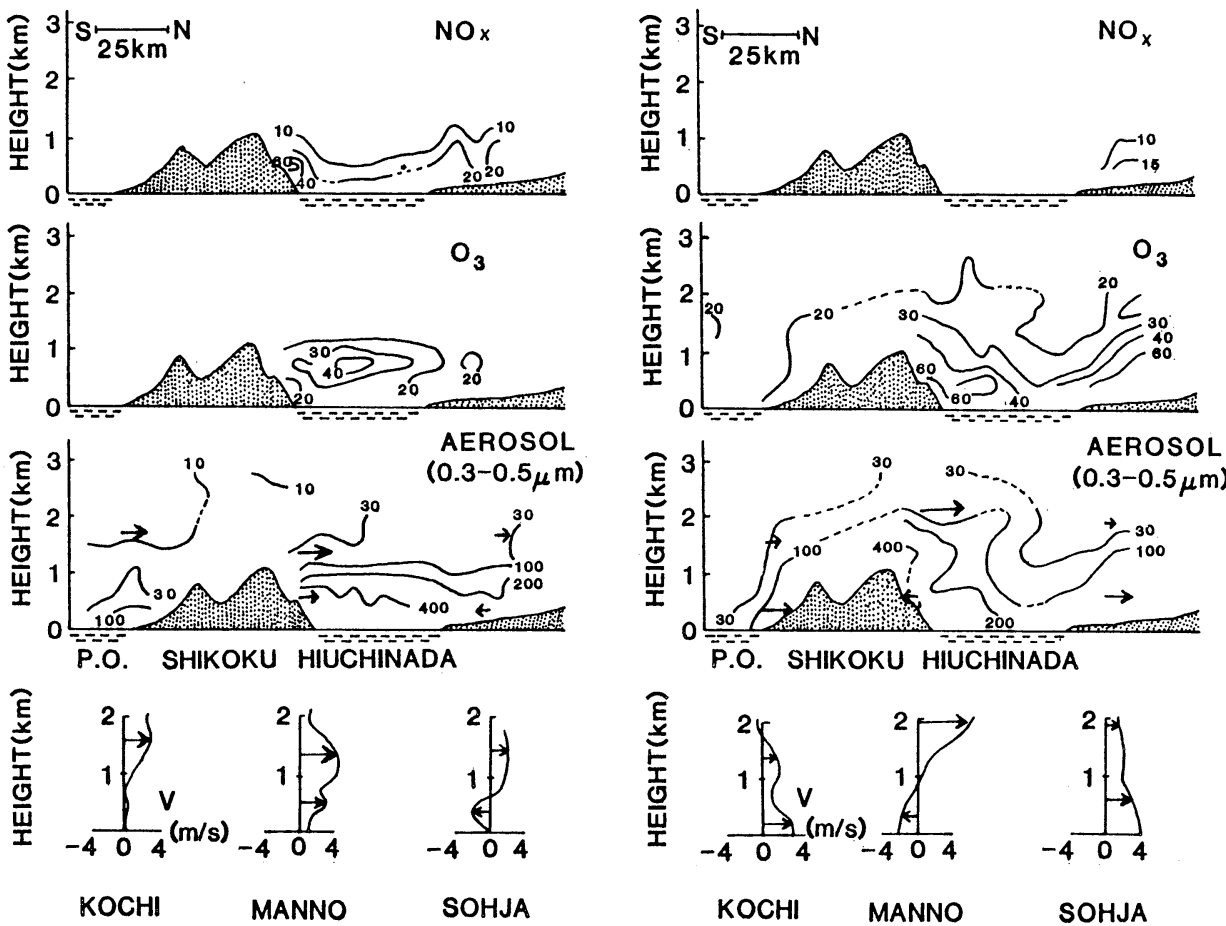

Fig. 6 Vertical cross-sections of concentrations in the early morning (left, Flight No. 8231) and in the afternoon (right, Flight No. 8233) on 29 July 1982. Top: NOx (ppb), second: ozone (ppb), third: particle (relative value), bottom: vertical profiles of north-south component of wind velocity at Kochi, Manno and Sohja.

It has also been pointed out by some recent numerical studies that upslope wind generated by the heated slope of the mountain has a large ability to carry pollutants from the lower level to the upper level over the mountain. Kimura (1983) carried out a numerical experiment of photochemical air pollution under a local wind system over a simplified two-dimensional terrain including the sea and a plain with a mountain inland. He pointed out that the mountain acts as a suction pump which transports pollutants from the plain to the upper layer above the mountain in the daytime, because the upslope wind is strong enough and has a sufficient thickness especially in the afternoon. The downslope wind, however, is generated in a thin layer near the surface and its velocity is not so large; therefore, only a small portion of air pollutants is carried back to the plain by the downslope wind in the nighttime. As a result, the greater part of the polluted air which was transported by the upslope wind remains in the upper layer over the mountain early in the following morning. Kondo (1983) calculated Lagrangian flow patterns of a simulated three-dimensional local circulation around the Harima area, which is situated in the eastern part of the Inland Sea. $\mathrm{He}$ also got almost the same results as those mentioned above.

The simulated transport processes of the pollutants around the mountain obtained by these numerical models agree well with our aircraft observation results. However, we could not clearly find the pollutants at upper levels over the Shikoku mountains in the early morning flights in 1982. In the case of our observation, the vertically transported air pollutants may have been carried to the east during the night by the westerly synoptic scale wind in the upper layer. On the other hand, no synoptic wind is assumed in these numerical models.

The aircraft traversed the developed convective cloud over the Shikoku mountains at an altitude of $2800 \mathrm{~m}$ in the evening of 29 July 


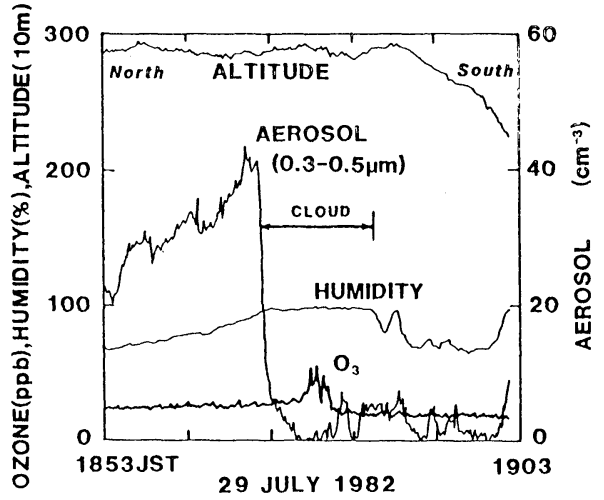

Fig. 7 Altitude, concentration of particle, relative humidity and ozone concentration observed crossing a cumulonimbus cloud from north to south on 29 July 1982 .

1982 (Figure 7). The concentration of aerosol is very high over the Hiuchinada side but extremely low over the Pacific Ocean side. Just as the aircraft entered the cumulus cloud, aerosol abruptly diminished and quite a high concentration of ozone was measured in the cloud. Although there still remains the problem of measuring in cloud, the data suggests the scavenging of aerosol and the strong vertical transport of ozone from the lower levels by cumulus convection. However, the latter could not be definitely concluded because of the reduction of aerosol.

From the discussions described above, the transport process by the local circulation in the Hiuchinada area is summed up as follows: During the night, air pollutants are transported to the Inland Sea and stratified in the stable layer by downslope winds and/or land breezes. In the lower layer over Hiuchinada, ozone has been removed by the reaction with NOx which has a very high concentration. In the daytime, air pollutants are transported to the land and then rise to nearly $3000 \mathrm{~m}$ in height by upslope winds and/or sea breezes (this level is much higher than that over the Kanto Plain). A portion of the polluted air is captured in the developed cumulus clouds over the mountains. The concentration of pollutants over the central part of the Inland Sea becomes low due to subsidence.

\section{Structure of the internal boundary layers}

For the experimental flights in 1981, the spatial distribution of humidity fluctuations was measured using a Lyman-alpha hygrometer. Figures $8 \mathrm{a}$ and $8 \mathrm{~b}$ show the spatial distributions of measured absolute humidity, its variance, surface temperature and altitude on the course between Osaka and Hiuchinada (see Figure 2a) on two consecutive days. The fluctuation in humidity is defined as a departure from the 1 minute running mean. It is easy to distinguish land from sea by the surface temperature, since over land the surface temperature is obviously higher with large fluctuations.

As may be seen in Figure 8a, on the first day absolute humidity is high and its variance (indicated as a root mean square in the figures) is large over the land because there the mixed layer is fully developed in the daytime as compared with that over the sea. Taking the flight to Hiuchinada for example, we can easily recognize the regions corresponding to land or sea (that is, internal boundary layers originating from land or sea) on the basis of whether or not absolute humidity is greater than $15 \mathrm{~g} / \mathrm{m}^{3}$. These regions are slightly shifted to the west (about 6-11 km) by the weak easterly wind $(2 \mathrm{~m} / \mathrm{s})$. Those observed in the flight to Osaka, however, are somewhat vague because the land-surface temperature has fallen late in the afternoon.

In Figure 8b, internal boundary layers are a little harder to recognize due to the stronger easterly wind $(6-7 \mathrm{~m} / \mathrm{s})$ on that day. Taking note of the Awaji island which has simple topographical features compared with Shikoku, the internal boundary layer over the island is greatly shifted to the west by the strong easterly wind. The shift on the flight from Hiuchinada is relatively small $(16 \mathrm{~km})$ compared with that to Hiuchinada $(42 \mathrm{~km})$. This can be explained as a result of the increase of heat flux due to the land-surface temperature rise. If Figure $8 \mathrm{~b}$ is further examined in detail, the shift of the internal boundary layer over the land is smaller than that over the sea. In other words, the internal boundary layer from land is observed to be broader. That is because the depth of the internal boundary layer increases more rapidly with downwind distance over land than over sea.

In order to clarify the effects of surface temperature and wind velocity upon the growth 


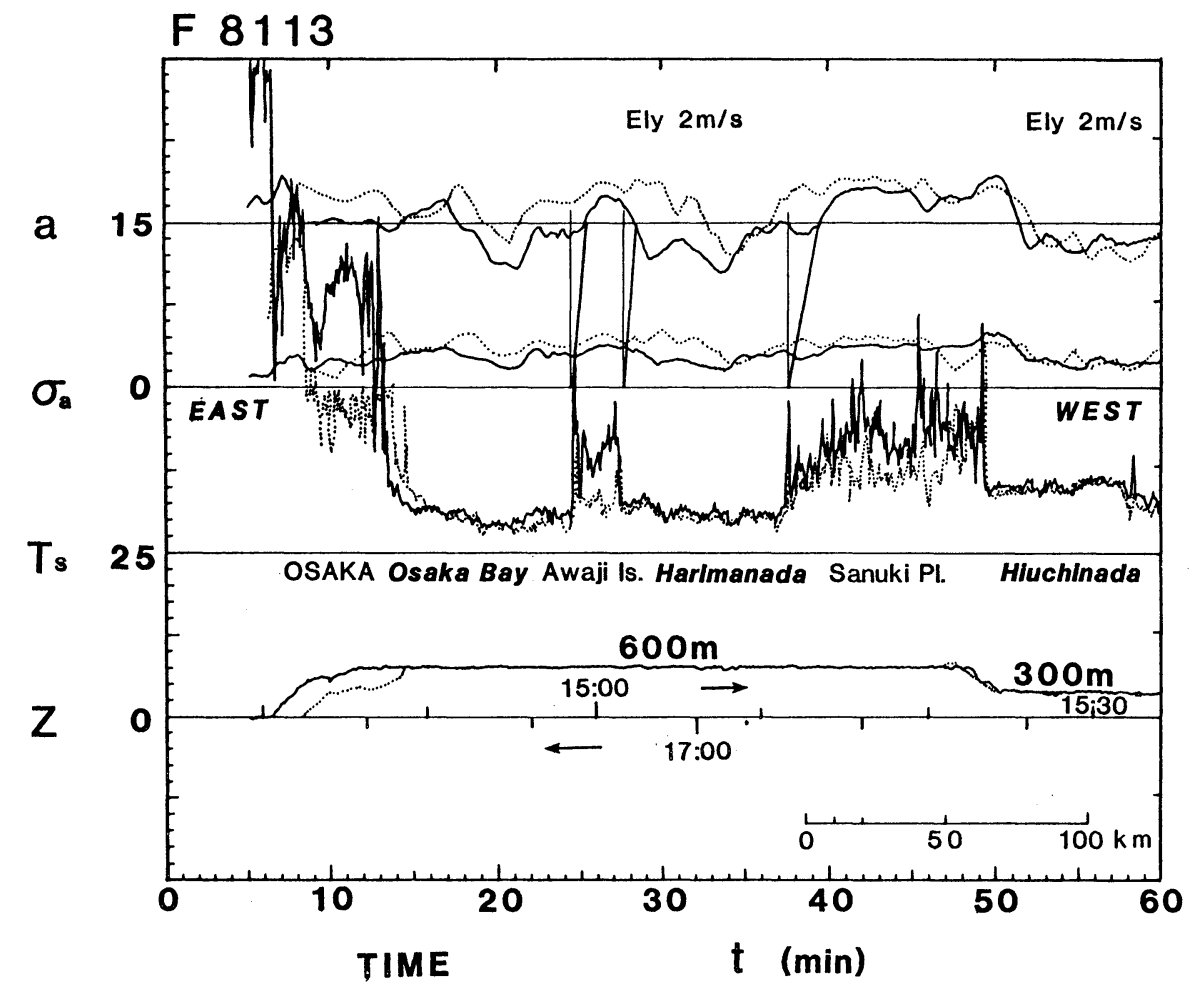

Fig. 8a Absolute humidity (a) and its variance ( $\left.\sigma_{\mathrm{a}}\right)$, surface temperature (Ts) and alitude (Z) on the course to (solid lines) and from (dotted lines) Hiuchinada on 19 August 1981.

of the internal boundary layer, its height is estimated by a simple boundary layer model. The outline of the model is described in the Appendix. In this model, we assume a uniform synoptic wind from the sea to a flat land region. At the windward boundary over the sea, a constant geostrophic wind velocity is assumed, and the constant vertical gradient of potential temperature is given by the average value in the observation. The roughness for the land surface, $z_{0}$, is assumed to be $0.5 \mathrm{~m}$. Sea-surface and land-surface temperatures are each homogeneous, and the difference between them is given by $\triangle T$.

The thick solid line in Figure 9 shows the height of the internal boundary layer with the fetch from the coast when the geostrophic wind velocity, $U$, is $7 \mathrm{~m} / \mathrm{s}$ and $\Delta T$ is $8 \mathrm{~K}$. This case corresponds to the flight from Hiuchinada on 20 August 1981. Here the height of the internal boundary layer is defined as the border where the diffusivity $\mathrm{K}$ is equal to $1.0 \mathrm{~m}^{2} / \mathrm{s}$. The thick broken line shows the case of the same geostrophic wind but $\Delta T=5 \mathrm{~K}$ which corresponds to the flight to Hiuchinada on that day. The fetch where the height of the internal boundary layer becomes $600 \mathrm{~m}$ (the altitude of the observational flight) is $17 \mathrm{~km}$ and $36 \mathrm{~km}$ in the cases of $\Delta T=8 \mathrm{~K}$ and $\Delta T=5 \mathrm{~K}$, respectively. These values agree quite well with the observed ones over the Awaji island, $16 \mathrm{~km}$ and $42 \mathrm{~km}$. The thin broken line in the figure shows the case $\triangle T=5 \mathrm{~K}$ and $U=2 \mathrm{~m} / \mathrm{s}$, which corresponds to the flight to Hiuchinada on 19 August. The fetch where the internal boundary layer becomes $600 \mathrm{~m}$ high is about $14 \mathrm{~km}$, which is much larger than the observed fetch $(6 \mathrm{~km})$. The reason for the disagreement must be that the boundary layer model neglects the effects of convection generated by the horizontal gradients of atmospheric temperature. Kimura (1976) examined a linear theory for heat islands and pointed out 


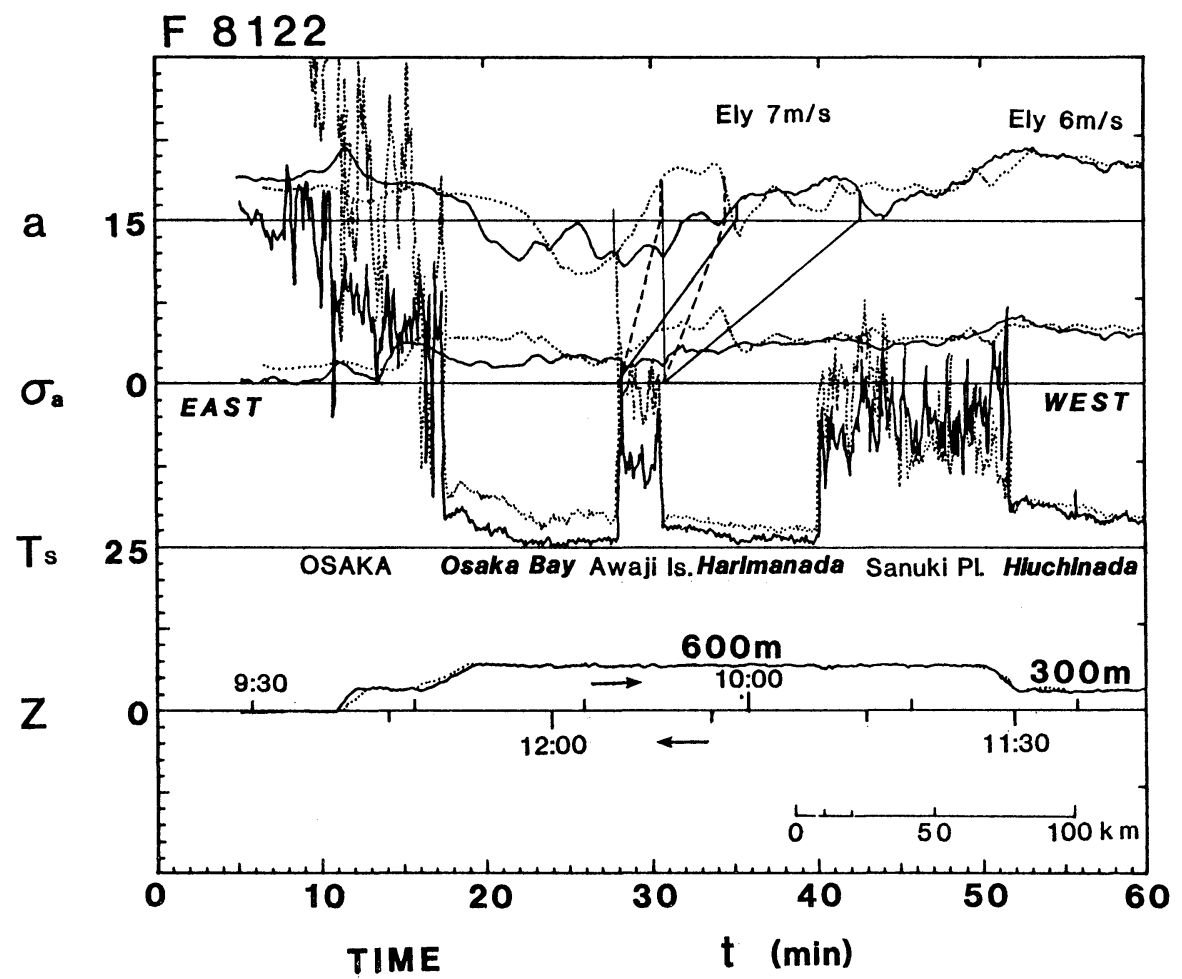

Fig. 8b Same as in Fig. 8a, but on 20 August.

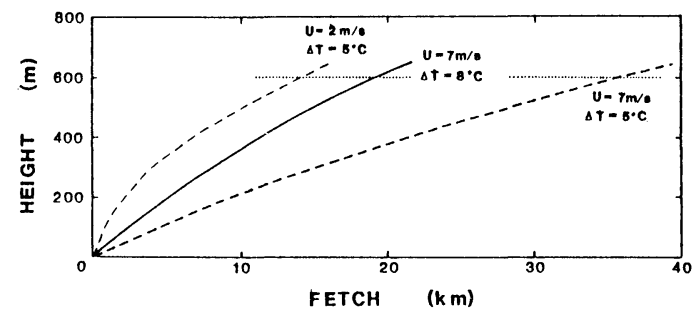

Fig. 9 Internal boundary layer simulated by a one-dimensional boundary layer model. The dotted line indicates the altitude of the observational flight.

that the effect of convection is important when the geostrophic wind is mild. If we assume that the horizontal scale of the island is $15 \mathrm{~km}$ and the vertical momentum diffusivity is $5 \mathrm{~m}^{2} / \mathrm{s}$, then the critical synoptic wind velocity is estimated to be about $5 \mathrm{~m} / \mathrm{s}$.

\section{Summary and conclusions}

Aircraft measurements of air pollutants and meteorological elements can be very effectively used in investigating transport processes by the local circulation. In the experimental study in 1980-82, some air pollutants such as NOx, ozone and aerosol were taken as tracers to examine the medium-range transport. Among them, ozone was the most suitable because of its long life and a concentration high enough to discriminate from the background value. On the other hand, the simultaneous measurement of NOx is considered to be indispensable, since NOx is closely connected with ozone through chemical reaction during a medium-range transport.

The medium-range transport process of air pollutants by the local circulation in the Hiuchinada area can be summarized as follows:

(1) In the early morning, polluted air is in general horizontally distributed over almost all of Hiuchinada in the layer below $1000 \mathrm{~m}$ in height.

(2) In the daytime, polluted air is transported to upper levels and then rises to nearly $3000 \mathrm{~m}$ 
in the evening. The lower layer becomes divergent and pollutants are carried to the coast due to the upslope wind, which is developed mainly on the Shikoku side. As a result, two highconcentration levels appear occasionally over Hiuchinada in the evening: one near the surface, and one above the mountain range.

(3) Air pollutants transported to upper levels seem to remain till sunrise the next morning; however this could not be fully investigated in this study.

(4) Developed cumulus clouds over mountains seem to contribute to the vertical transport of ozone and the scavenging of aerosol.

Besides obtaining new knowledge about the transport of polluted air, the structure of the internal boundary layers formed over the complex terrain was analyzed. It was found that higher values of absolute humidity and its variance appeared over the land where the mixed layer was fully developed, and its shift to the west due to the easterly wind was observed. The analyzed structure of the internal boundary layers agrees quite well with a simple model simulation.

\section{Acknowledgements}

This research was carried out as part of the chain of the special projects designed to clarify the behavior of secondary pollutants over complex terrain from the meteorological point of view. The project, sponsored by Japan Environmental Agency, was accomplished by members of Applied Meteorology Research Division in Meteorological Research Institute, JMA. The authors express their thanks to Mr. I. Sato, Dr. K. Takeuchi in MRI and Dr. P.C. Manins and Dr. J.L. McGregor in CSIRO for their useful comments.

\section{Appendix}

\section{A simple model of the internal boundary layer}

To estimate the height of the internal boundary layer, we apply a simple one-dimensional model, which is based upon the following equations:

$$
U \frac{\partial u}{\partial x}=f v+\frac{\partial}{\partial z}\left(K_{m} \frac{\partial u}{\partial z}\right)
$$

$$
\begin{aligned}
& U \frac{\partial v}{\partial x}=-f(u-U)+\frac{\partial}{\partial z}\left(K_{m} \frac{\partial v}{\partial z}\right) \\
& U \frac{\partial \theta}{\partial x}=\frac{\partial}{\partial z}\left(K_{h} \frac{\partial \theta}{\partial z}\right)
\end{aligned}
$$

where $x$ is a coordinate along the geostrophic wind $U, u$ and $v$ correspond to $x$ and $y$ components of wind velocity, $\theta$ is the potential temperature, $f$ is the Coriolis parameter and $K_{m}$ and $K_{h}$ are the vertical diffusivities of momentum and heat, respectively.

In these equations, pressure gradient terms are neglected except for the large-scale pressure gradients which are balanced by the geostrophic wind. We have also neglected horizontal diffusion terms and advection terms except for those of the geostrophic wind. The height of the model atmosphere is about $3000 \mathrm{~m}$ and is divided into 50 layers with smaller intervals in the lower layers. The lowest grid point is taken at the.level of $8 \mathrm{~m}$ and the grid interval is $50 \mathrm{~m}$ above $140 \mathrm{~m}$ in height. The equations are integrated numerically by the Crank-Nicolson method.

A constant flux layer is assumed under the lowest level $(8 \mathrm{~m})$. The momentum flux $\tau$ and the heat flux $H$ in this layer, which give the boundary conditions of equations (1)-(3), are calculated using the similarity law by the same method as that by Kimura et al. (1983). The vertical diffusivities, $K_{m}$ and $K_{h}$, in equations (1)-(3) are estimated from the turbulent closure model (level 2) given by Mellor and Yamada (1974).

\section{References}

Blumenthal, D.L., W.H. White and T.B. Smith, 1978: Anatomy of a Los Angeles smog episode: pollutant transport in the daytime sea breeze regime. Atmos. Environ., 12, 839-907.

Edinger, J.G., 1973: Vertical distribution of photochemical smog in Los Angeles Basin. Envir. Sci. Technol., 7, 247-257.

Gloria, H.R., G. Brandburn, R.F. Reinisch, J.N. Pitts, Jr., J.V. Behar and L. Zafonte, 1974: Airborne survey of major air basins in California. J. Air Pollut. Control Ass., 24, 645-652.

Husar, R.B., D.E. Patterson, D.L. Blumenthal, W.H. White and T.B. Smith, 1977: Three-dimensional distribution of air pollutants in the Los Angeles Basin. J. Appl. Met., 16, 1089-1096.

Kimura, R., 1976: Effects of general flows on a heat island convection Part 1: Linear theory for the 
uniform flow. J. Meteor. Soc., 54, 308-320.

Kimura, F. 1983: A numerical simulation of local winds and photochemical air pollution (1): Two-dimensional land and sea breeze. J. Meteor. Soc. Japan, $61 ; 862-878$.

and S. Arakawa, 1983: A numerical experiment on the nocturnal low level jet over the Kanto plain.J. Meteor. Soc., 61, 848-861.

Kondo, H., 1983: A numerical experiment for the local circulation around Harima area (2): An example of Lagrangian flow. Bull. Nat. Res. Inst. Poll. \& Res., 13, 75-83.

Mellor, G.L. and T. Yamada, 1974: A hierarchy of turbulence closure model for planetary boundary layers. J. Atmos. Sci., 31, 1791-1805.

Mizuno, T. and N. Higuchi, 1979: On the measurement of ozone concentration in the lower $3000 \mathrm{~m}$ of the suburbs of Tokyo. Kogai, 14, 49-59 (in Japanese). Murayama, N., A. Harada, T. Yoshikawa, S. Arakawa, J. Sato, F. Kimura, T. Toya, T. Kobayashi, T. Koide, N. Yano, Y. Suzuki, I. Sato and S. Kurita, 1984: Observations and numerical experiment on local circulation and medium-range transport of air pollutants. Tech. Rep. Meteor. Res. Inst., 11, pp. 311 (in Japanese with English Synopsis and Figure captions).

Tsuruta, H., 1983: Report of Special Research Project on Environmental Science, Ministry of Education, Culture and Science. B163-R114, 92-141 (in Japanese).

Wakamatsu, S., Y. Ogawa, K. Murano, K. Goi and Y. Aburamoto, 1983: Aircraft survey of the secondary photochemical pollutants covering the Tokyo Metropolitan area. Atmos. Environ., 17, 827-835.

\title{
複雑地形上での局地風による污染質の中距離輸送の 航空機観測
}

\section{戸矢 時 義・木 村 富 士 男・村 山信 彦 \\ (気象研究所)}

\begin{abstract}
瀬戸内海烼灘地域で航空機により大気污染質と気象要素の立体観測を1980年から82年にかけて毎夏行 い，局地風による污染質の輸送過程を調べた。

污染大気は，早朝瀬戸内海のほぼ全域に $1000 \mathrm{~m}$ 以下の高度で広がっており，午後には四国側で谷風／ 海風により上空に輸送され，夕方には $3000 \mathrm{~m}$ 高度に達する。

発達した積雲の中を横切った観測から，積雲はオゾンを上空へ輸送するとともにエーロゾルの強い除 去作用を持っている可能性が示唆された。さらに，複雑地形上で形成された内部境界層を観測し，その 構造を解析した。観測された内部境界層の構造は，簡単な境界層モデルによるシミュレーションと一致 する。
\end{abstract}

* 現在所属: 気象衛星センター 